\title{
The airborne multi-wavelength water vapor differential absorption lidar WALES: system design and performance
}

\author{
M. Wirth • A. Fix • P. Mahnke • H. Schwarzer • \\ F. Schrandt • G. Ehret
}

Received: 30 October 2008 / Revised version: 17 December 2008

(c) Springer-Verlag 2009

\begin{abstract}
A high-performance airborne water vapor differential absorption lidar has been developed during the past years. This system uses a four-wavelength/three-absorption line measurement scheme in the $935 \mathrm{~nm} \mathrm{H}_{2} \mathrm{O}$ absorption band to cover the whole troposphere and lower stratosphere simultaneously. Additional high spectral resolution aerosol and depolarization channels allow precise aerosol characterization. This system is intended to demonstrate a future space-borne instrument. For the first time, it realizes an output power of up to $12 \mathrm{~W}$ at a high wall-plug efficiency using diode-pumped solid-state lasers and nonlinear conversion techniques. Special attention was given to a rugged optical layout. This paper describes the system layout and technical realization. Key performance parameters are given for the different subsystems.
\end{abstract}

PACS 42.65.Yj · 42.68.Wt · 92.60.Jq

\section{Introduction}

The primary objective of the project WALES (derived from WAter vapor Lidar Experiment in Space) of the DLR

\author{
M. Wirth $(\varangle) \cdot$ A. Fix $\cdot$ G. Ehret \\ Deutsches Zentrum für Luft- und Raumfahrt (DLR), Institut \\ für Physik der Atmosphäre, Oberpfaffenhofen, Münchner Str. 20, \\ 82234 Wessling, Germany \\ e-mail: martin.wirth@dlr.de \\ P. Mahnke \\ Deutsches Zentrum für Luft- und Raumfahrt (DLR), Institut \\ für Technische Physik, Stuttgart, Germany \\ H. Schwarzer $\cdot$ F. Schrandt \\ Deutsches Zentrum für Luft- und Raumfahrt (DLR), Institut \\ für Robotik und Mechatronik, Berlin, Germany
}

(Deutsches Zentrum für Luft- und Raumfahrt) was the preparation of a space-borne mission to overcome the shortcomings of radio-sondes and passive satellite sensors in mapping the global water vapor distribution. While the former do not cover the globe uniformly and do not provide reliable water vapor observations in the upper troposphere and lower stratosphere, the latter suffer from insufficient vertical resolution and accuracy [1]. In contrast, a spaceborne multi-wavelength $\mathrm{H}_{2} \mathrm{O}$-DIfferential Absorption Lidar (DIAL) could provide global water vapor observations suitable for a reliable assessment of its temporal and spatial evolution. These data would lead to an improved description of climate processes in general circulation models (GCMs) and to benefits in numerical weather prediction (NWP) [2].

The methodology of DIAL has been developed during the late 1960s and 1970s, and a large number of studies appeared in the following years, see $[3,4]$ for a review of the principle of measurement and [5, 6] for an overview of existing systems. First proposals for a space-borne $\mathrm{H}_{2} \mathrm{O}-\mathrm{DIAL}$ dating back to the 1980s and 1990s [6, 7] suffered from a high power-aperture product, driving the system costs and lacking coverage of the upper troposphere. To overcome these problems, a measurement scheme was developed at DLR that uses four wavelengths in the $935 \mathrm{~nm}$ absorption band of $\mathrm{H}_{2} \mathrm{O}$, each one especially adapted to a restricted altitude range of the atmosphere. Figure 1 shows the absorption cross section of water vapor in this wavelength region near ground and at $10 \mathrm{~km}$ altitude and indicates possible lines for DIAL measurements. In this way, relatively large absorption coefficients can be chosen, which allow for short averaging times even at high noise levels, thus lowering the system's power-aperture product considerably [2, 9-11].

One major step undertaken during recent years to validate the four-wavelength concept was the realization of an airborne demonstrator. This instrument not only implements 
the basic multi-wavelength concept envisaged for a space WALES but is also based on laser technologies which are suited for in-space operation by using high-efficiency solidstate lasers and nonlinear conversion techniques. Special at-

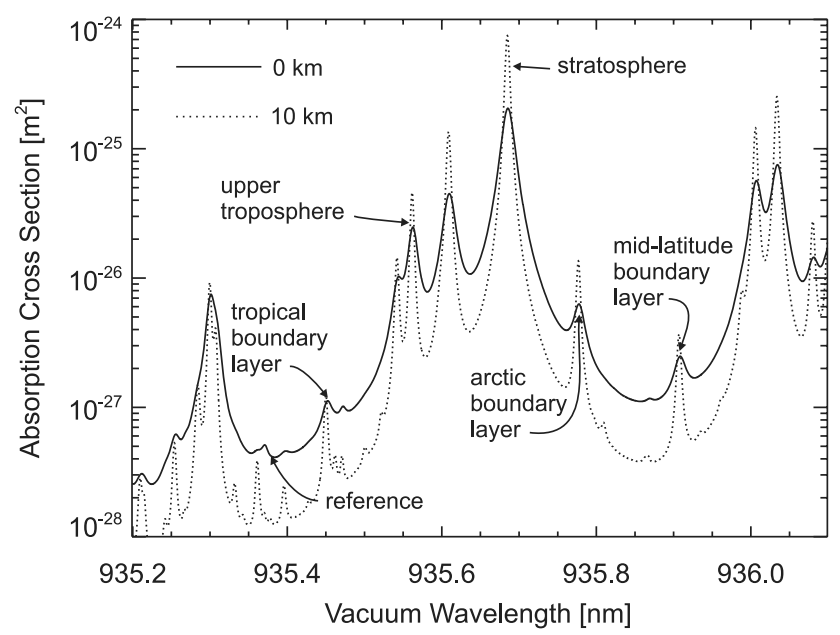

Fig. $1 \mathrm{H}_{2} \mathrm{O}$-absorption lines used for the WALES demonstrator. Absorption cross section data calculated from HITRAN 2006 [8] for sea level conditions (solid line) and at $10 \mathrm{~km}$ altitude (dashed line) using the US-standard atmosphere. Possible wavelengths of operation are indicated by arrows, where the current system is able to use four at a time tention has also been given to a rugged optical layout avoiding large resonators and long beam paths. The assembly of the new instrument was finished in Summer 2007, and first measurements were carried out on board the DLR research aircraft Falcon F20 during the field experiments COPS (July 2007) [12], SAMUM II (Jan./Feb. 2008) [13], IPY-Thorpex (Feb./Mar. 2008) [14], EUCAARI (May 2008), and T-PARC (Aug./Sept. 2008). Results of these activities will be presented in separate publications.

\section{Transmitter layout}

The basic requirement for the transmitter system was to generate nanosecond single-frequency light pulses at four wavelengths between 935 and $936 \mathrm{~nm}$ having a total average power in the range of $10 \mathrm{~W}$. Based on the experience with its precursor system $[15,16]$, it was decided to use an Nd:YAG laser in master oscillator/power amplifier configuration followed by two nonlinear conversion stages (see Fig. 2).

First, the radiation of the pump laser is frequency doubled by a second-harmonic generator (SHG) and then converted to a wavelength of $935 \mathrm{~nm}$ by an optical parametric oscillator (OPO), both stages using potassium titanyl phosphate (KTP) as the nonlinear material. The output of the OPO is repetitively switched between two wavelengths at a
Fig. 2 Block diagram and pulse timing scheme of the transmitter. Two identical chains of lasers and non-linear conversion stages are used to generate pulsed radiation on four selectable wavelengths between 935 and $936 \mathrm{~nm}$. Each transmitter module is alternated between two wavelengths at a rate of $50 \mathrm{~Hz}$. The time difference $\Delta t$ between output pulses of the transmitters may be set to an arbitrary offset. Currently a value of $5 \mathrm{~ms}$ is used, resulting in an equidistant pulse-train. Additionally, the unused pump radiation at 1064 and $532 \mathrm{~nm}$ is transmitted to the atmosphere for aerosol lidar measurements

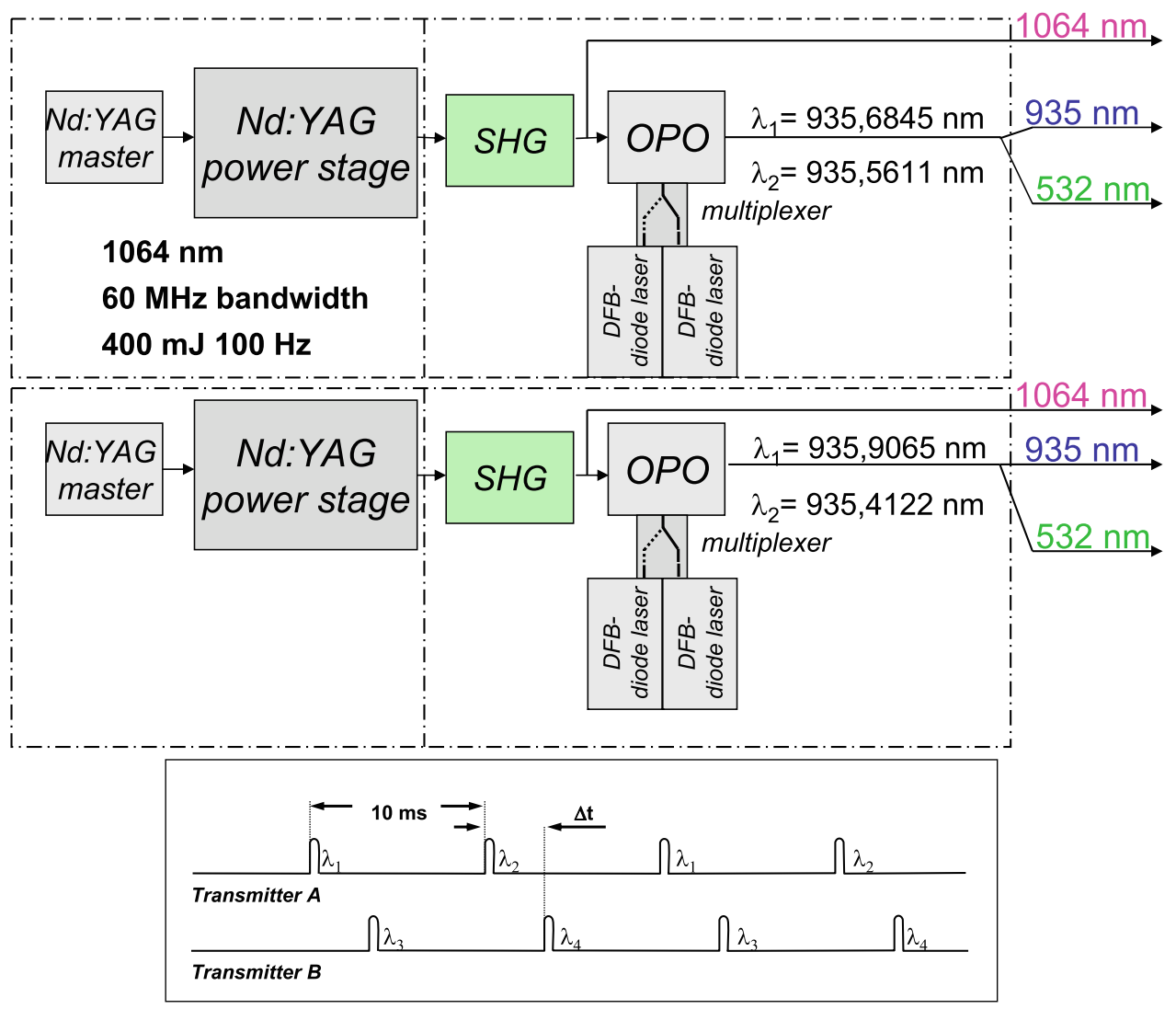




\begin{tabular}{ll}
\hline Table 1 Transmitter performance parameters & \\
\hline Parameter & Value \\
\hline Repetition rate per laser & $100 \mathrm{~Hz}$ \\
Pump laser pulse energy @ $1064 \mathrm{~nm}$ & $400 \mathrm{~mJ}$ \\
Pump laser pulse energy @ 532 nm & $220 \mathrm{~mJ}$ \\
System output @ $1064 \mathrm{~nm}$ & $120 \mathrm{~mJ}(160 \mathrm{~mJ})^{\mathrm{a}}$ \\
System output @ $935 \mathrm{~nm}$ & $45 \mathrm{~mJ}(60 \mathrm{~mJ})^{\mathrm{a}}$ \\
System output @ 532 nm & $75 \mathrm{~mJ}(100 \mathrm{~mJ})^{\mathrm{a}}$ \\
Pulse length @ $1064 \mathrm{~nm}$ & $8 \mathrm{~ns}(\mathrm{FWHM})$ \\
Pulse length @ 935 nm & $5.5 \mathrm{~ns}(\mathrm{FWHM})$ \\
Pulse length @ 532 nm & $7.5 \mathrm{~ns}(\mathrm{FWHM})$ \\
Beam quality $M^{2} @ 1064 \mathrm{~nm}$ & 1.5 \\
Beam quality $M^{2} @ 935 \mathrm{~nm}$ & 7.6 \\
Beam quality $M^{2} @ 532 \mathrm{~nm}$ & 1.8 \\
Beam divergence (all) & $1 \mathrm{mrad}$ \\
Line width @ 1064 nm & $54 \mathrm{MHz}(\mathrm{FWHM})$ \\
Line width @ 935 nm & $150 \mathrm{MHz}(\mathrm{FWHM})$ \\
Frequency stability @ $1064 \mathrm{~nm}$ & $\leq 1 \mathrm{MHz}$ \\
Frequency stability @ 935 nm & $\leq 30 \mathrm{MHz}$ \\
Spectral purity @ 935 nm & $\geq 99.9 \%$ \\
Spectral purity @ 532 nm & $\geq 99.995 \%$ \\
\hline
\end{tabular}

${ }^{a}$ Energy values in brackets are valid for a reduced spectral purity of $99 \%$

rate of $50 \mathrm{~Hz}$. Two identical laser systems are operated temporally interleaved, resulting in a total pulse rate of $200 \mathrm{~Hz}$ and a repetition rate for the four-wavelength pulse train of $50 \mathrm{~Hz}$ (see Fig. 2). The residual pump radiation at 1064 and $532 \mathrm{~nm}$, which is not converted by SHG and/or OPO, is also transmitted into the atmosphere and used for aerosol measurements. Table 1 summarizes measured values for the most important performance parameters of the transmitter. The individual sub-systems are described in more detail in the following sections.

\subsection{Pump laser}

To guarantee stable single-mode operation, the master oscillator is implemented as a passively Q-switched monolithic $\mathrm{Nd}$ :YAG ring laser [17] with inherent longitudinal mode selection (MephistoQ, Innolight $\mathrm{GmbH}$ ). For highest stability under pressure/temperature changes and vibrations, the optical components of this laser were integrated into a custommade pressure-tight, monolithic housing. This master laser operates at a repetition rate of $4 \mathrm{kHz}$ with an output energy of $40 \mu \mathrm{J}$ per pulse at $1064 \mathrm{~nm}$. The pulse length is $7.7 \mathrm{~ns}$ full width at half maximum (FWHM).

The frequency of this laser is temperature-tunable with a coefficient of $3.86 \mathrm{GHz} / \mathrm{K}$. Each $4.5 \mathrm{GHz}$ a mode hop occurs. The free spectral ranges overlap by nearly half of their

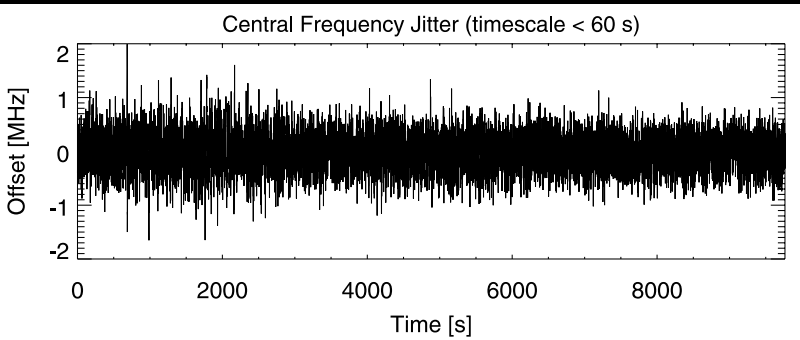

Central Frequency Jitter Histogram (timescale $<60 \mathrm{~s}$ )

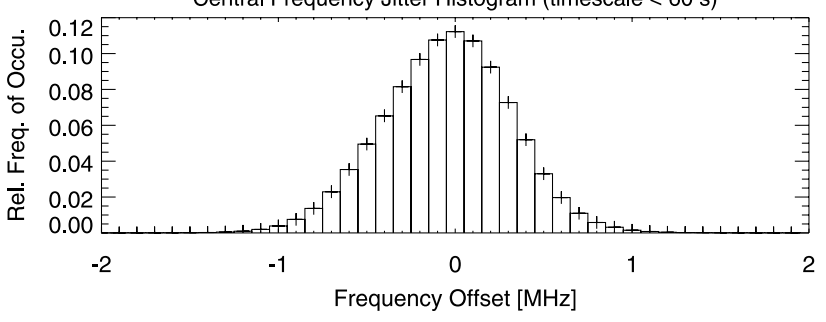

Fig. 3 Time series and histogram of the pulse-to-pulse frequency jitter of the Nd:YAG master oscillator, measured against a Lightwave 124-1064-100 CW laser using a heterodyne technique. Measurements were taken at the pump repetition rate of the amplifier chain $(100 \mathrm{~Hz})$. Since the reference laser was not absolutely stabilized, variations on time scales larger than one minute were removed by high pass filtering

width, so that for each given wavelength, it is always possible to find a temperature where the laser runs stably in a single longitudinal mode. In addition it is possible to modulate the output wavelength of the master oscillator by inducing a small amount of mechanical stress on the laser crystal. This is done by a piezo transducer and allows for a full wave modulation of up to $30 \mathrm{MHz}$. Both, temperature and stress tuning schemes are used to stabilize the laser to a iodine $\left(\mathrm{I}_{2}\right)$ line for High Spectral Resolution Lidar (HSRL) measurements of aerosol extinction (see [18] for an explanation of this technique). To accomplish the locking to the $\mathrm{I}_{2}$-line, the laser is stress-modulated with a $100 \mathrm{~Hz}$ sine wave in phase with the pump pulse for the power amplifier stages (see below). Part of the output radiation is frequency doubled in a 10-mm-long KTP crystal and transmitted through a 50mm-long absorption cell, filled with about $50 \mathrm{~Pa}$ of iodine. A standard lock-in technique is used to stabilize the laser to the line center by controlling the oscillators crystal temperature. Typically the $\mathrm{I}_{2}$ line at $18787.8098 \mathrm{~cm}^{-1}$ (line 1109 according to [19]) is used for HSRL measurements. The absolute stability is estimated to be better than $1 \mathrm{MHz}$, and the short-term $(<60 \mathrm{~s})$ pulse-to-pulse frequency jitter was measured to be better than $300 \mathrm{kHz}$ RMS (see Fig. 3) using a heterodyne technique [20-22].

Since the master oscillator is passively Q-switched, the timing of the output pulses is not controllable on a shot-toshot basis. To synchronize the timing to the power amplifier stages, the current of the pump laser diode of the master is controlled by a phase-locked loop. The residual timing jitter is below $\pm 1 \mu$ s as can be seen from Fig. 4. This is sufficient 
to synchronize the master laser to the pump pulse of the amplifier chain. The timing of the lidar data acquisition, where a lower jitter is mandatory, is triggered by the outgoing light pulses.

A three-stage amplifier chain, side-pumped by diodes, is used to achieve the desired output pulse energy. The amplifiers are pumped at a repetition rate of $100 \mathrm{~Hz}$ and syn-
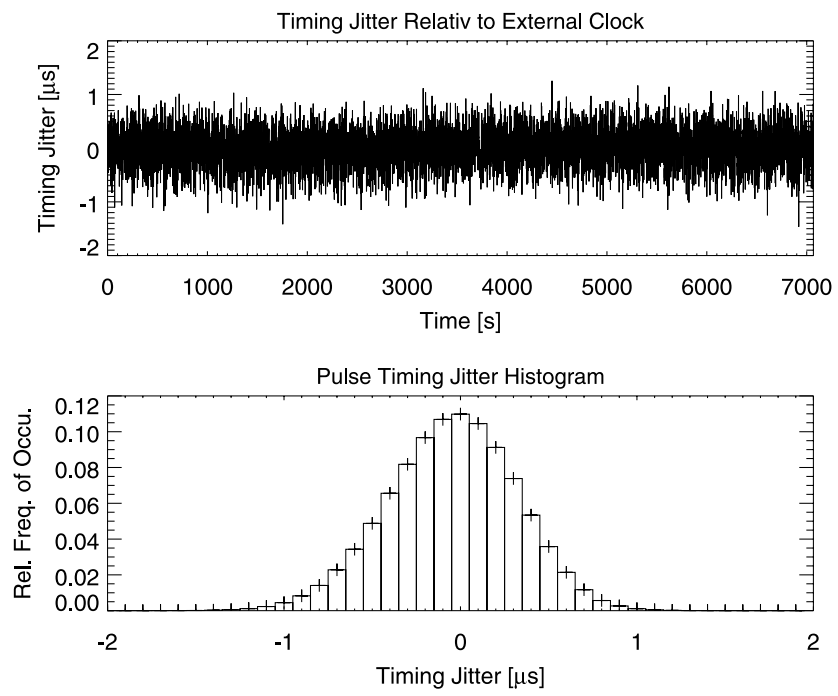

Fig. 4 Time series and histogram of the pulse-to-pulse timing jitter of the Nd:YAG master oscillator relative to an external clock source. Measurements were taken at the pump repetition rate of the amplifier chain $(100 \mathrm{~Hz})$ chronized with the master oscillator using a phase-locked loop (see Fig. 5), i.e., every 40th master oscillator pulse is amplified. Within each amplifier pump chamber, 60 quasicontinuous-wave (QCW) laser diodes emitting at $808 \mathrm{~nm}$ are arranged in a five-fold symmetry around the $110 \mathrm{~mm}$ long Nd:YAG rod. These diodes are operated at a current of 85 A resulting in a total optical power of $5 \mathrm{~kW}$ per chamber. The pump chambers were designed by Rofin Sinar AG and use diodes from DILAS GmbH.

The preamplifier stage uses an Nd:YAG rod with $3 \mathrm{~mm}$ diameter and $0.9 \% \mathrm{Nd}$ doping. For a pump duration of $140 \mu \mathrm{s}$, the resulting single-pass small-signal gain is approximately 100 . The preamplifier is built up in a polarizationcoupled double pass configuration. For better compensation of the thermally induced birefringence within the laser rod, a Faraday rotator is used for polarization rotation after the first pass [23]. The total saturated double-pass gain is about 120 resulting in an output pulse energy of $50 \mathrm{~mJ}$. Since the preamplifier has a very high double-pass small-signal gain of more than $10^{4}$, it is very sensitive to back-reflections. Therefore Faraday isolators are put into the entrance and exit paths of this stage. A half-wave plate mounted into a motorized rotation stage allows control of the input energy to the main amplifier stages.

The main amplifier uses two identical pump chambers, each equipped with rods of $6 \mathrm{~mm}$ diameter, $110 \mathrm{~mm}$ length and $0.5 \% \mathrm{Nd}$ doping. Operated at $220 \mu$ s pump-pulse duration, these stages give a total saturated gain of more than
Fig. 5 Schematic optical layout of the pump laser

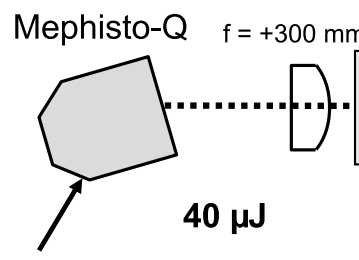

synchronisation $4 \mathrm{kHz} / 100 \mathrm{~Hz}$
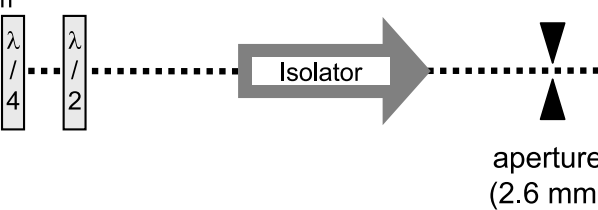

$(2.6 \mathrm{~mm})$
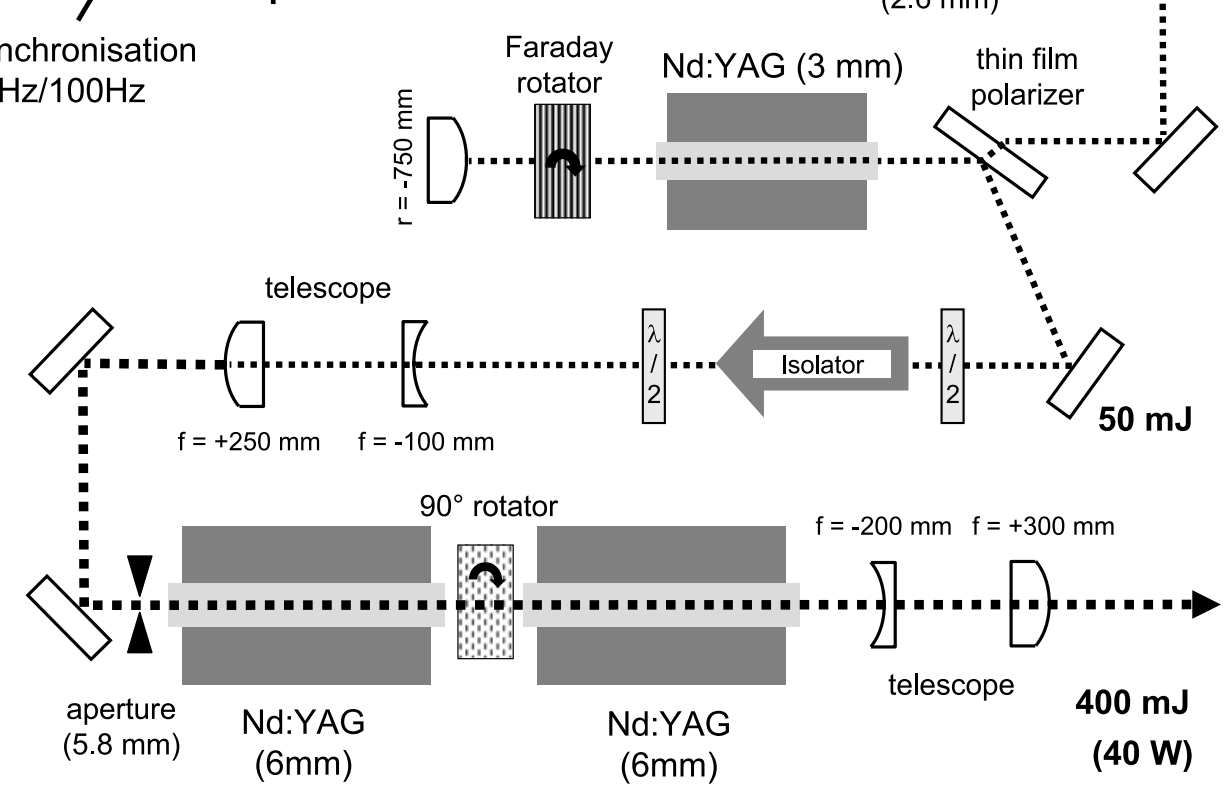

$(6 \mathrm{~mm})$
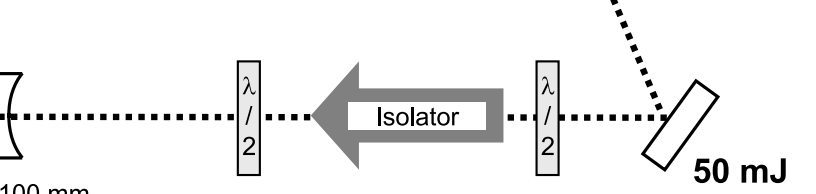

$90^{\circ}$ rotator

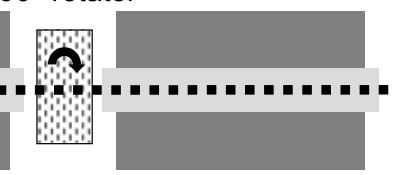

$f=-200 \mathrm{~mm} \quad \mathrm{f}=+300 \mathrm{~mm}$

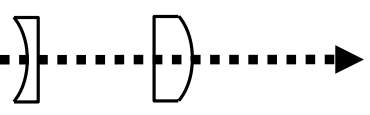

telescope

$\mathrm{Nd}: Y A G$

$(6 \mathrm{~mm})$

(40 W) 


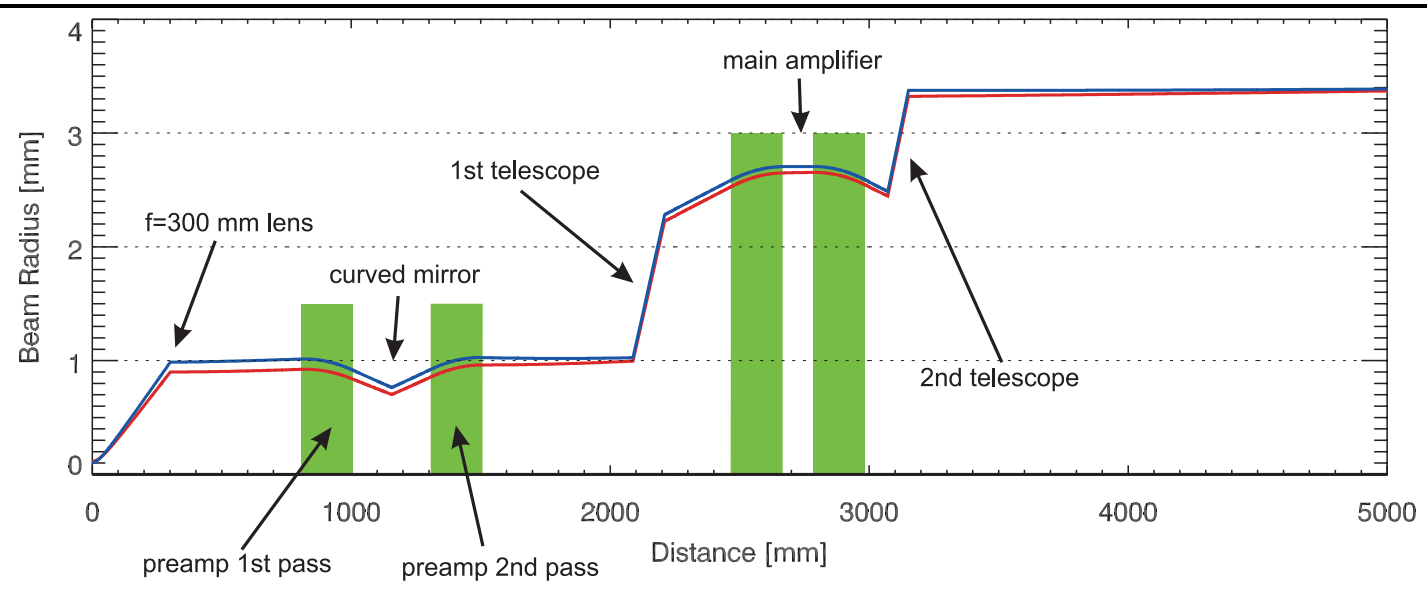

Fig. 6 Pump laser beam propagation calculations. Shown are the nominal second-moment radii for both axes of the beam. The master laser is located at distance zero

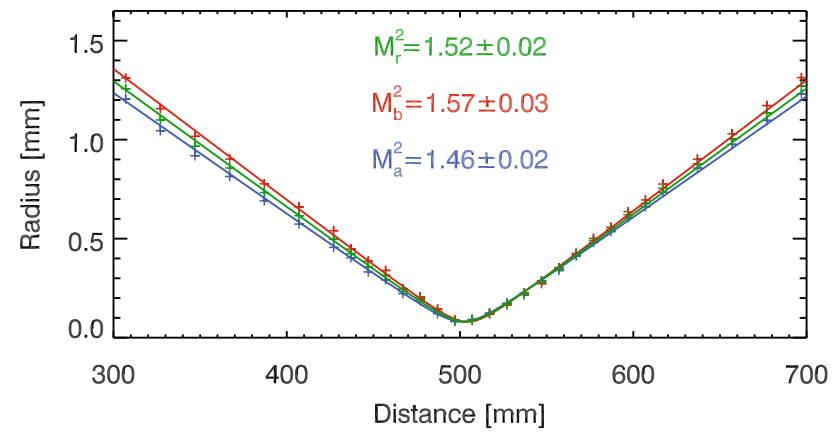

Fig. 7 Measurement of beam propagation parameter $M^{2}$ at the fundamental wavelength of the pump laser at $405 \mathrm{~mJ}$ pulse energy. Data shown for the principal axis $a$ (blue) and $b$ (red) and the equivalent radius $r=\sqrt{r_{a} r_{b}}$ (green)

8 resulting in a total output pulse energy $>400 \mathrm{~mJ}$. A $90^{\circ}$ polarization rotator in between the two chambers is used for birefringence compensation [23].

The thermal lens induced by a radial thermal gradient within the rods is compensated by means of a convex mirror $(R=750 \mathrm{~mm})$ for the preamplifier and two adjustable telescopes before and after the main amplifier stages. To guide a proper layout and adjustment of these compensation elements, Gaussian beam propagation calculations were performed. Figure 6 shows the nominal beam radius along the optical path of the laser. The beam propagation parameter $M^{2}$ was adjusted within each rod to measured values to account for distortions caused by spatially nonuniform amplification, beam truncation, and higher-order thermal aberrations. The $M^{2}$ values measured after the oscillator, preamplifier first pass, preamplifier second pass, first main amplifier, and second main amplifier (whole laser) are in this order: 1.05, 1.1, 1.2, 1.35, and 1.5. Figure 7 shows a beam parameter measurement for the total laser at $405 \mathrm{~mJ}$ output pulse energy. The beam propagation parameter was measured according to the second-moment method as described

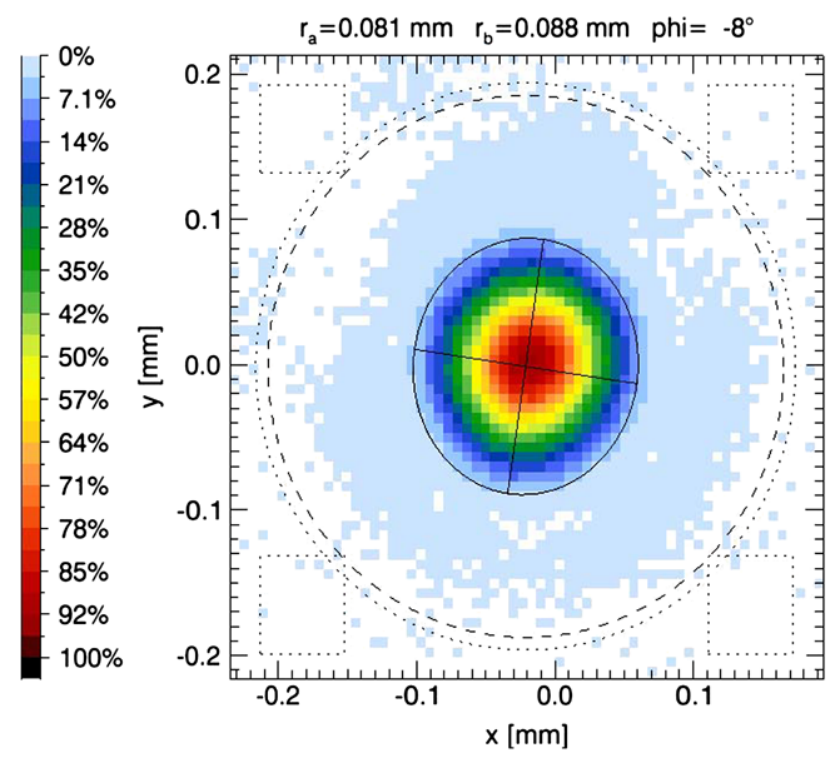

Fig. 8 Far-field beam profile of the Nd:YAG pump laser at the fundamental wavelength and a pulse energy of $405 \mathrm{~mJ}$. The solid drawn ellipse shows the second-moment radius determined according to the ISO11146 standard. The background is estimated from the rectangular regions shown near the corners

by the ISO11146 [24] standard using an $f=500 \mathrm{~mm}$ lens and a CCD camera with $6.75 \mu \mathrm{m}$ spatial resolution (see Fig. 8 for a single-beam profile measurement). Since the beam of the master laser is slightly elliptical, calculations are shown for both principal axes. These calculations were verified by beam parameter measurements at various points along the optical axis. The beam propagation through the main amplifiers was chosen symmetrically with respect to the plane of the $90^{\circ}$ polarization rotator to optimize the effect of birefringence compensation (see $[23,25,26]$ and references therein). 

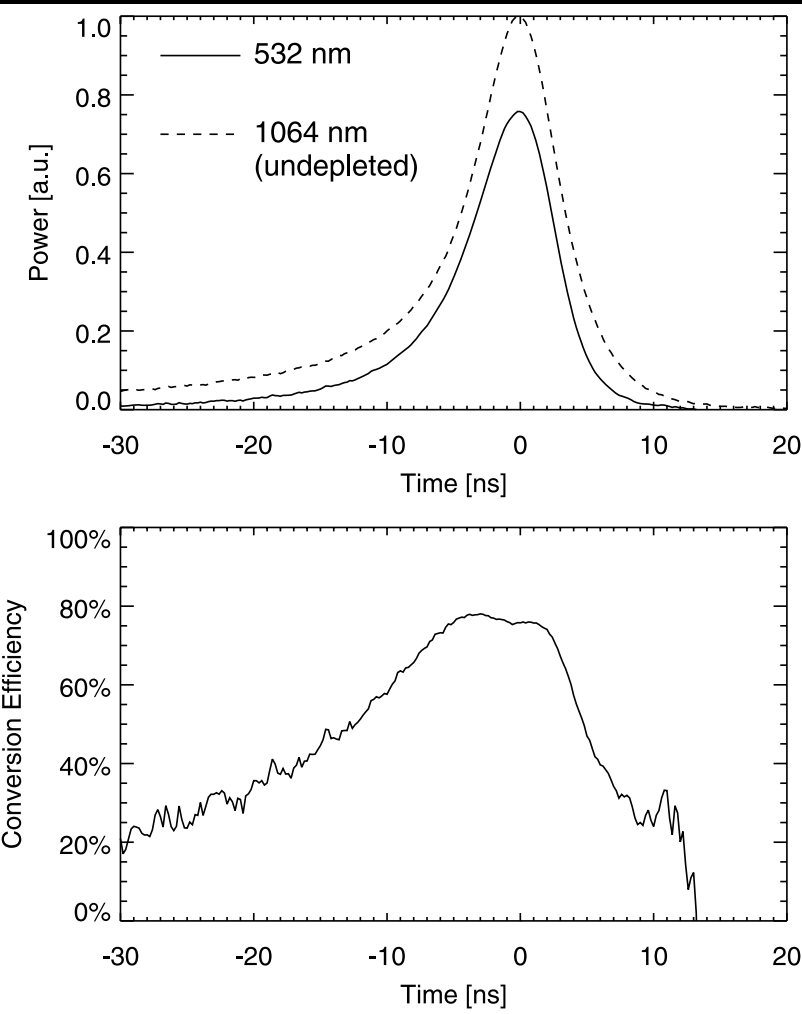

Fig. 9 Temporal pulse shapes of the (undepleted) fundamental radiation and the frequency-doubled light (upper panel). The lower panel shows the time-resolved conversion efficiency. See main text for details of measurement

The fundamental radiation from the Nd:YAG laser is frequency doubled using a $10 \mathrm{~mm} \times 10 \mathrm{~mm} \times 10 \mathrm{~mm}$ potassium titanyl phosphate $\left(\mathrm{KTiOPO}_{4}\right.$ or KTP) crystal in Type II configuration $(o e \rightarrow o)$. At full laser power, a conversion efficiency of $55 \%$ is reached, which allows the OPO to be pumped with energies of up to $220 \mathrm{~mJ}$.

Figure 9 shows the temporal shapes of the (undepleted) $1064 \mathrm{~nm}$ pulse and the $532 \mathrm{~nm}$ pulse measured with a $2 \mathrm{GHz}$ bandwidth $0.2 \mathrm{~mm}$ diameter Si-photo-diode at the center of the beam profile. The lower panel shows the corresponding conversion efficiency, which reaches peak values of up to $80 \%$. A special feature of the passively Q-switched oscillator, which can be seen in Fig. 9, is the slowly increasing leading slope of the pulse. The pulse at $1064 \mathrm{~nm}$ has a total length of about $100 \mathrm{~ns}$, whereas the FWHM is $\approx 8$ ns only. Since the range resolution of the lidar system is about $15 \mathrm{~m}$, corresponding to a time resolution of $100 \mathrm{~ns}$, this feature has no effect on the lidar measurements. Of course the total doubling efficiency could be enhanced by suppressing the leading edge of the pulse (e.g., by Pockels cell), but this has not been implemented yet to keep the system setup simple.

The SHG crystal from Cristal Laser S.A. is temperaturestabilized to about $80^{\circ} \mathrm{C}$ to reduce the risk of gray-track formation [27]. After a mechanical coarse adjustment phase

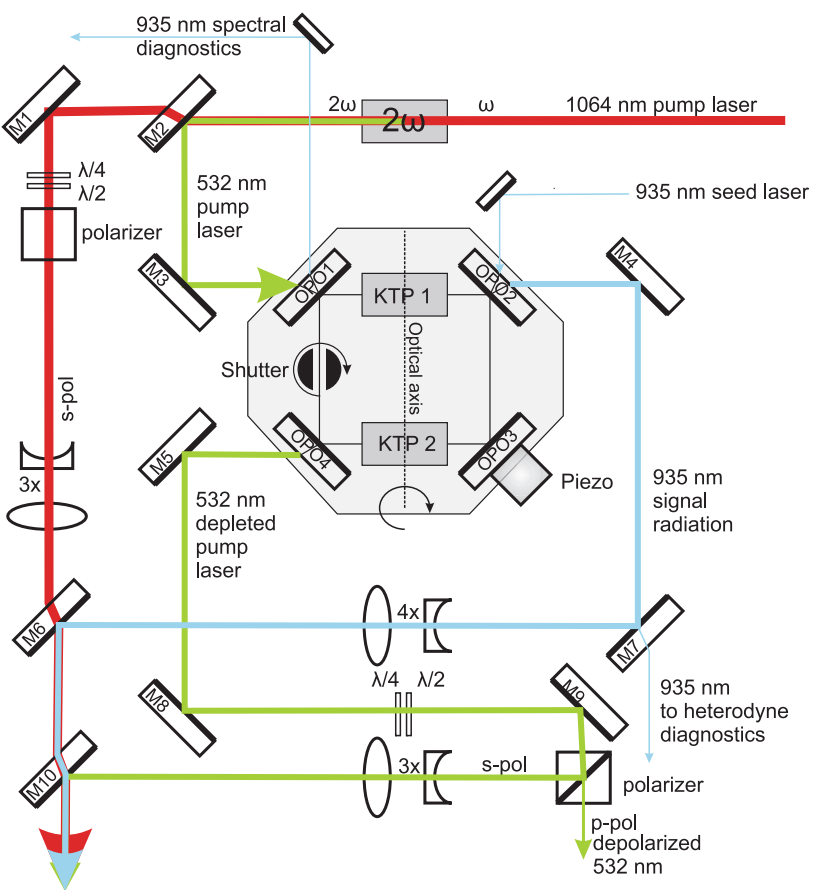

Fig. 10 Optical layout of the OPO for $935 \mathrm{~nm}$ generation. The central four mirror ring resonator is surrounded by additional optics to reestablish a linear polarization for the remaining pump radiation and to recombine all beams on a common axis after appropriate expansion by adjustable telescopes

matching is optimized by temperature tuning to avoid a vibration-sensitive kinematic mount.

The whole pump laser including the optics and all electronic subsystems like power supply and diode drivers is integrated into a single housing with $701 \mathrm{~mm} \times 412 \mathrm{~mm} \times$ $257 \mathrm{~mm}$ dimensions. Only the water-cooling loop, operating at $33^{\circ} \mathrm{C}$ to prevent condensation under high-humidity environmental conditions, is housed in an external unit. The electrical power consumption at full optical output power of $40 \mathrm{~W}$ at $1064 \mathrm{~nm}$ is $750 \mathrm{~W}$, thus giving a wall-plug efficiency of $5.3 \%$.

\subsection{Frequency converter (OPO)}

The OPO is realized as a walk-off-compensated, injectionseeded, dual-crystal, singly-resonant planar four-mirror ring-oscillator with idler dumping between the crystals. The principal design has been described by Mahnke et al. [28] Figure 10 shows the optical layout together with the beam conditioning and recombination optics for the aerosol wavelengths. The optical length of the cavity is $15 \mathrm{~cm}$, resulting in a longitudinal-mode separation of $2.0 \mathrm{GHz}$.

The two $10 \mathrm{~mm} \times 10 \mathrm{~mm} \times 10 \mathrm{~mm} \mathrm{KTP} \mathrm{crystals} \mathrm{are}$ mounted on a common rotation stage for a coarse wavelength setting. The total tuning range of the OPO is about $\pm 10 \mathrm{~nm}$, limited by mechanical constraints of the crystal rotation stage and the dielectric coatings of the mir- 


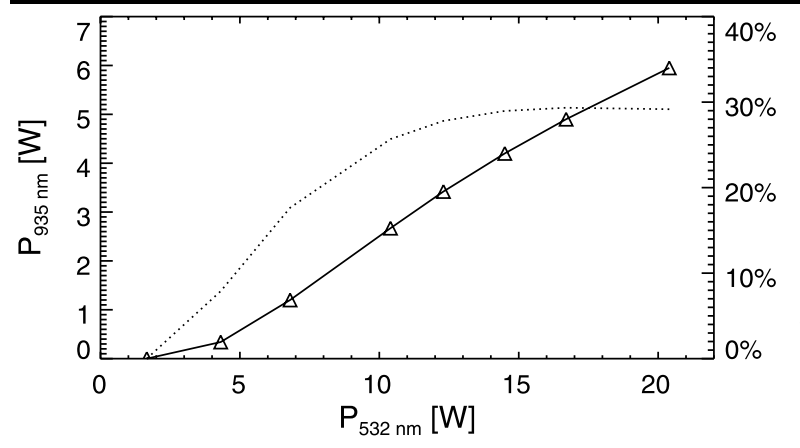

Fig. 11 Mean output power (solid) and conversion efficiency (dashed) from 532 to $935 \mathrm{~nm}$ of the OPO as functions of the incident average pump power at $100 \mathrm{~Hz}$ repetition rate. Measurement shown is for unseeded operation

rors. But, due to the restricted tuning range of the seed lasers, only wavelengths between 935.0 and $936.0 \mathrm{~nm}$ are accessible without an exchange of components within the seed laser system. For fine tuning and fast switching of the phase-matching angle, each crystal is mounted on its own piezo-transducer-driven flexure stage. The fine tuning range is $\pm 0.5 \mathrm{~nm}$, so all $\mathrm{H}_{2} \mathrm{O}$ absorption lines shown in Fig. 1 are selectable on a shot-by-shot basis. An intra-cavity shutter allows the OPO to be switched off for diagnostic purposes (e.g., measurement of pump depletion) and a second remotely controllable shutter allows the seed beam to be blocked for an optimal adjustment of the central wavelength of the free-running OPO.

The output coupler has a reflectivity of $30 \%$ which was found to give optimum results [28]. Figure 11 shows the output power of the OPO at $935 \mathrm{~nm}$ as a function of the pump power at $532 \mathrm{~nm}$ and the corresponding conversion efficiency. The measurement shown is for unseeded operation. The output at full pump power is about $5 \%$ higher if the OPO is seeded. The OPO threshold is at $1.7 \mathrm{~W}$, and no saturation by back conversion is noticeable up to a pump power of 12 times above threshold.

The beam propagation parameter $M^{2}$ at $935 \mathrm{~nm}$ is about 2.5 if the (seeded) OPO is operated 4 times above threshold but rapidly increases to 7.6 at full pump power (12 times above threshold). In unseeded mode the $M^{2}$ at full power reaches values larger than 10 . These values are not particularly low but are fully adequate for our application, since they allow to achieve the required divergence of $1 \mathrm{mrad}$ (see Table 1) with a beam diameter that fits through the aircraft window. At the same time, these values are in full accordance with the numbers reported in $[29,30]$. Other techniques to enhance the spatial beam profile of OPOs are the use of an image-rotating cavity-design [31-33] or a masteroscillator/power-amplifier setup as described in [34]. However, this would have lead to a higher complexity of the system without need.

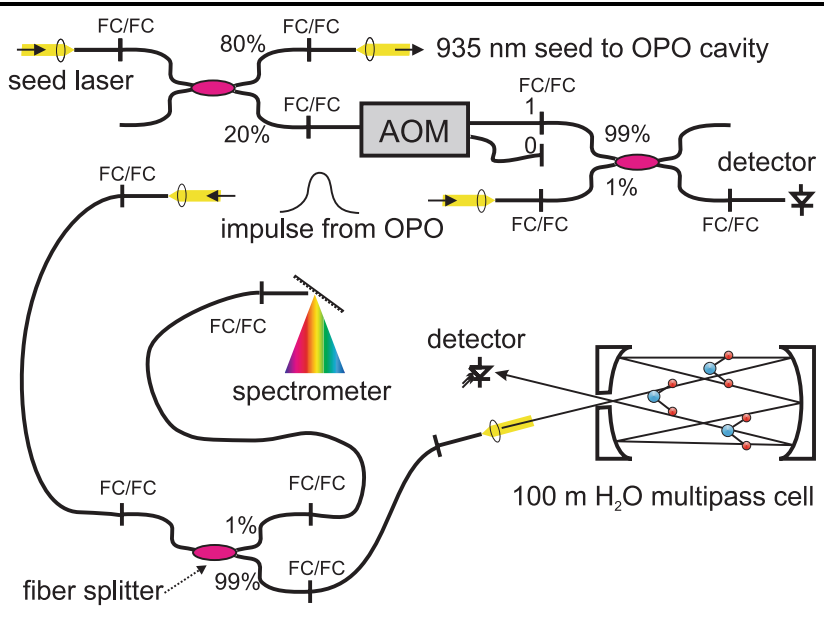

Fig. 12 OPO diagnostic setup. The leak of the outgoing radiation at $935 \mathrm{~nm}$ behind mirror M7 in Fig. 10 is coupled into a polarization-maintaining single-mode fiber and mixed with part of the frequency-shifted seed radiation on a fast photo-detector for monitoring the frequency of the transmitted pulse. The radiation leaking from mirror OPO1 in Fig. 10 is coupled into a multi-mode fiber and distributed to a grating spectrometer for coarse wavelength adjustment and a $100 \mathrm{~m}$ long multi-pass absorption cell for spectral purity monitoring. For clarity, only the components for one laser system are shown

To monitor a proper single longitudinal mode operation of the OPO, the frequency difference between the outgoing high power pulses and the seed radiation is measured on a shot-by-shot basis. For this purpose, part of the seed light $(\approx 100 \mu \mathrm{W})$ is frequency shifted with an acousto optic modulator (AOM) by $450 \mathrm{MHz}$ and mixed with the outgoing pulse on a fast (bandwidth $>1 \mathrm{GHz}$ ) photo diode. Figure 12 shows the optical layout of this-mostly fibercoupled - diagnostics. For each pulse, the beat signal is digitized by an $8 \mathrm{bit} / 2 \mathrm{GHz}$ transient recorder (Acqiris DC241), and its power spectrum is calculated by fast Fourier transform (FFT). Figure 13 shows a typical beat signal and the corresponding power spectrum. From the power spectrum the frequency offset of the output pulse relative to the seed laser is calculated as the centroid (or first moment) of the spectral distribution. This method is commonly used by heterodyne lidar for wind detection [35] or for laser diagnostics [20-22, 36-39].

In addition to the beat signal, a second fiber-coupled diagnostics branch includes a grating spectrometer (Ocean Optics HR4000) with $0.3 \mathrm{~nm}$ (FWHM) resolution for wavelength adjustment of the free running (i.e., unseeded) OPO and a multi-pass absorption cell (New Focus 5612) with an effective path length of $100 \mathrm{~m}$ (see Fig. 12). This cell is filled with about $1200 \mathrm{~Pa}$ of pure $\mathrm{H}_{2} \mathrm{O}$ and is used to measure the spectral purity of the OPO radiation, which is defined as the ratio of the energy within the seeded longitudinal mode and the total pulse energy (see [16] for a closer examination of this technique). At the $\mathrm{H}_{2} \mathrm{O}$-absorption line at $10687.36209 \mathrm{~cm}^{-1}$, the strongest line within the $935 \mathrm{~nm}$ 

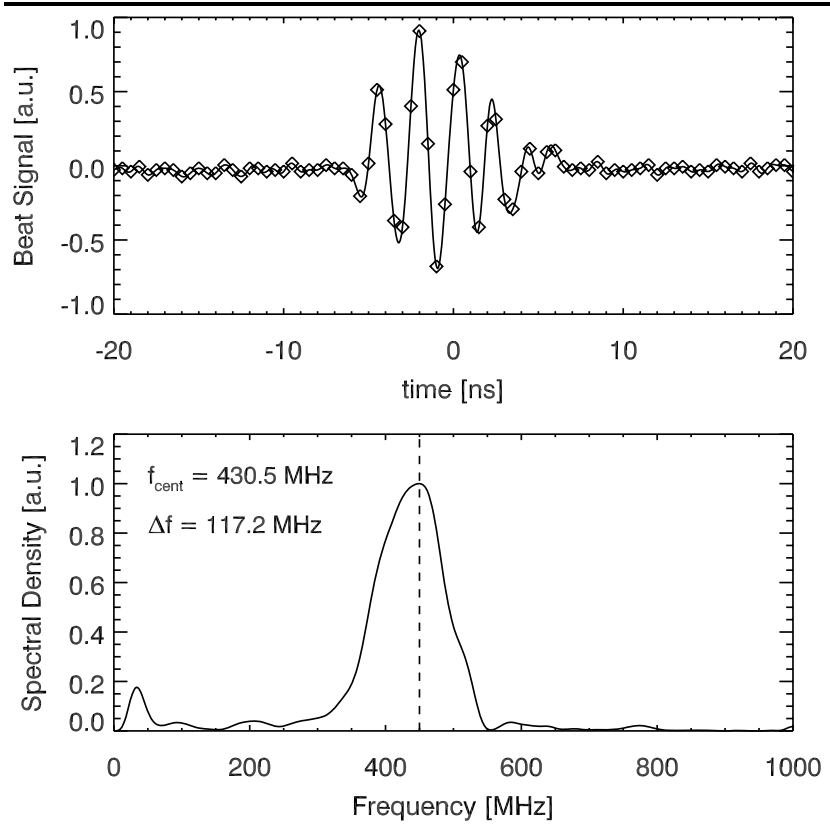

Fig. 13 Beat signal of the OPO output pulse with the frequency-shifted seed laser (upper panel). The diamonds show the actual sampled data points and the solid line is interpolated from them by the $\sin (x) / x$ interpolation kernel. The corresponding power spectrum with central frequency and bandwidth estimates is shown in the lower panel. The dashed vertical line marks the frequency offset generated by the AOM (450 MHz)

absorption band, the theoretical residual transmission of the cell is less than $10^{-16}$. At the same time, the broadband spectrum of the unseeded OPO is attenuated only by the factor 0.83 . Thus, any residual transmission through the cell is a direct measure of spectral impurity, as long as the spectral impure part of the OPO output has about the same spectral shape as the radiation from the unseeded OPO, an assumption which is supported by the studies [40, 41].

In order to enable optimum injection seeding, the resonator length has to be matched to a multiple of the wavelength of the seed radiation. For this purpose, one of the mirrors of the resonator ring is mounted on a piezo-electric transducer (OPO3 in Fig. 10). An error signal for the cavity control loop is generated by monitoring the frequency difference between the outgoing pulse and the seed radiation as measured by the heterodyne diagnostics described above. Figure 14 shows a measurement, where the OPO cavity length was scanned while the seed laser was stabilized to a strong water vapor absorption line at $10687.36209 \mathrm{~cm}^{-1}$. As can be seen from Fig. 14a, b, the OPO pulses show a strong mode in the spectral vicinity of the seed radiation which follows the tuning characteristics of the passive cavity in a range of $\pm 200 \mathrm{MHz}$. Panel (c) of Fig. 14 shows the corresponding transmission of the multi-pass cell indicating that only for a frequency difference near zero, $99.9 \%$ of the OPO radiation is concentrated within the central mode.

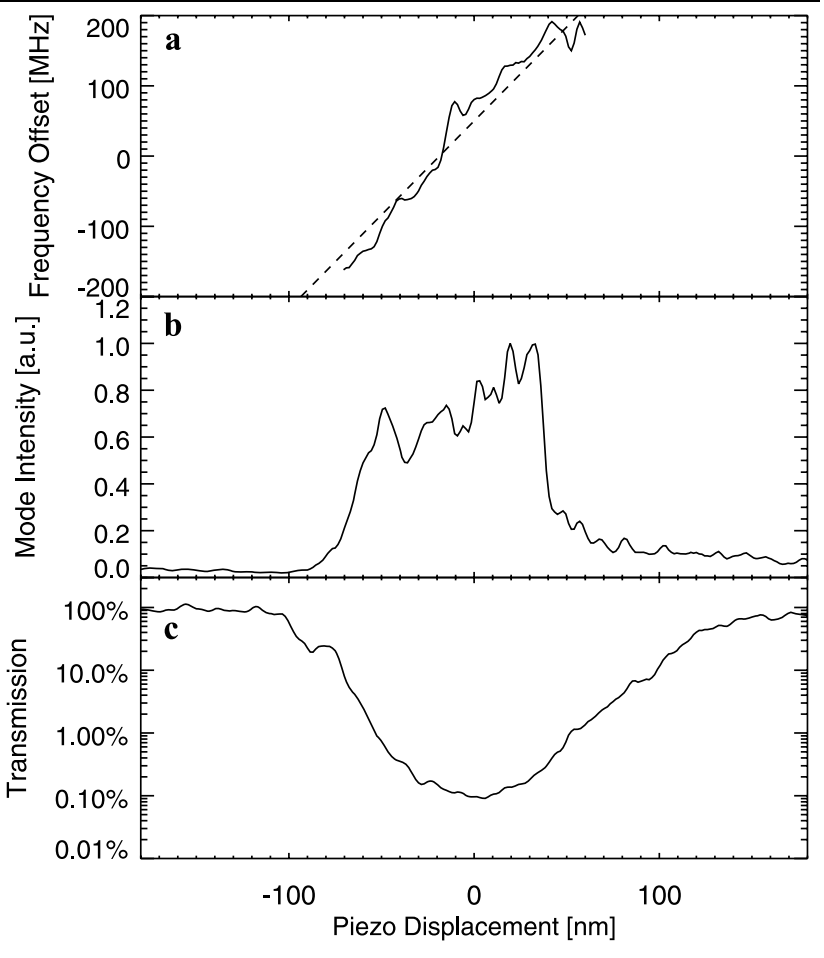

Fig. 14 Mode pulling of the OPO. a Frequency offset of the pulsed radiation relative to seed laser and calculated frequency tuning of the passive cavity (dashed). b Beat signal strength. $\mathbf{c}$ Transmission of the pulsed $935 \mathrm{~nm}$ radiation through a saturated $\mathrm{H}_{2} \mathrm{O}$-cell (for further explanation, see main text)

This type of cavity-length control was selected because most of the techniques typically used for lasers fail to work well for the OPO. The widespread buildup-time reduction method [42] is hard to apply because the time reduction of our OPO is only about 100-200 ps. Methods monitoring the transmission of the passive cavity like ramp-and-fire [43] or Pound-Drever-Hall [44] suffer from the fact that the finesse of the cavity with $70 \%$ output coupling is very low compared to the stability requirement of better than $1 / 100$ of the free spectral range, and no finesse enhancement by an active gain medium is present.

A disadvantage of the stabilization scheme used for the OPO is that it is not possible to react to vibrations with frequencies exceeding half the repetition rate of $50 \mathrm{~Hz}$. However, the OPO cavity is a small ring milled from a monolithic aluminum block and has a lowest resonance frequency of $2 \mathrm{kHz}$, which is well above the excitation spectrum from the aircraft. Within more than 300 hours, no disturbance of injection seeding by vibrations has been observed during actual flight operation.

For strong absorption lines, it is possible to monitor the spectral purity of the OPO radiation by means of the $100 \mathrm{~m}$ multi-pass cell. However, this method fails for the weaker $\mathrm{H}_{2} \mathrm{O}$-lines used for the boundary layer where a much longer cell would be necessary. Therefore a method was developed 


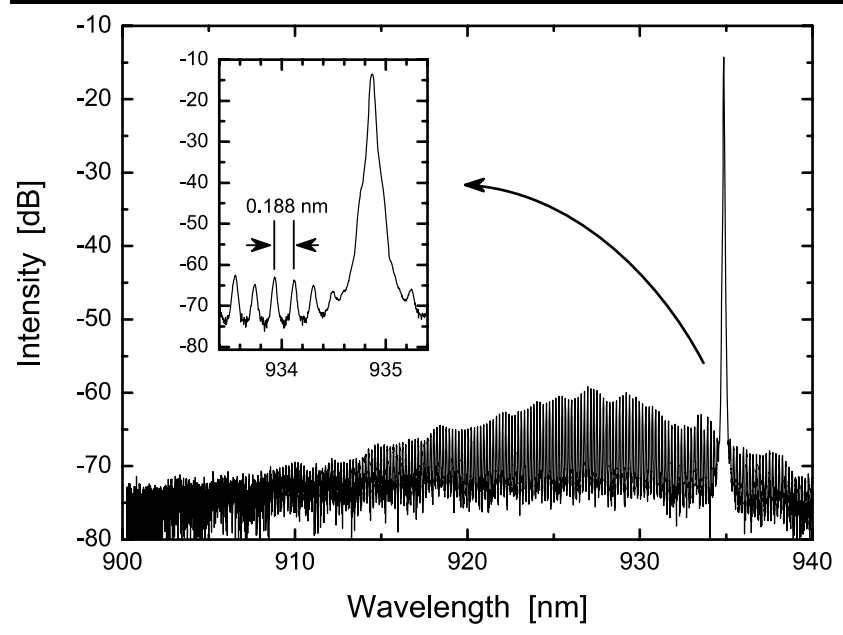

Fig. 15 Mode spectrum of the DFB lasers measured with an optical spectrum analyzer (ANDO AQ6317B). Only the next two nearest neighbors of the main mode fall into the gain range of the OPO

which measures the suppression of the first two side modes of the OPO by a technique similar to the heterodyne monitor for the central mode described above. This allows for an online optimization of the coupling of the seed beam into the OPO cavity and an offline selection of laser pulses with sufficient side-mode suppression and hence high spectral purity. Details will be discussed in a separate paper.

The different beams $(1064 \mathrm{~nm} / 935 \mathrm{~nm} / 532 \mathrm{~nm})$ are individually expanded to a diameter of about $20 \mathrm{~mm}$ and adjusted to a divergence of $1 \mathrm{mrad}$ to meet eye-safety restrictions at a distance of about $6 \mathrm{~km}$ from the transmitter. The wavelengths for aerosol measurements are fed through highpower polarizers to enable highly sensitive atmospheric depolarization measurements. All beams are combined by dielectric mirrors onto the same optical axis.

Currently, we have to reduce the pump energy of the OPO to about 7 times above threshold to get a spectral purity of better than $99.9 \%$. Further improvements to use the fully available pump energy are currently under discussion.

\subsection{Seed laser system}

To seed the OPOs, four independent distributed feedback (DFB) laser diodes are used. These diodes were manufactured by Nanoplus GmbH using a special process which allows the single-mode operating range of the lasers to be selected without an overgrow step and allows for a reasonable price at small quantities [45]. The diodes are operated at a current of $80 \mathrm{~mA}$, resulting in an output power of $35 \mathrm{~mW}$. The side-mode suppression is larger than $40 \mathrm{db}$ (i.e., $1 / 10^{4}$ ) in the vicinity of the main mode, which can be seen in Fig. 15. A good side mode suppression is essential to guarantee a good spectral purity of the OPO output.

The wavelength of the diodes can either be temperature or current controlled with coefficients of $\approx 0.068 \mathrm{~nm} / \mathrm{K}$ and $\approx 0.01 \mathrm{~nm} / \mathrm{mA}$, respectively. Temperature tuning by a Peltier element between 20 and $35^{\circ} \mathrm{C}$ allows the (vacuum) wavelength to be set to an arbitrary value within the interval from 935.0 to $936.0 \mathrm{~nm}$. After the wavelength of a DFB-diode has settled to within about $0.001 \mathrm{~nm}$, we switch to the faster current tuning to stabilize the wavelength to an $\mathrm{H}_{2} \mathrm{O}$-absorption line.

To keep the bias for DIAL measurements in the lower stratosphere below $1 \%$, an absolute frequency stability of better than $60 \mathrm{MHz}$ is required [9]. For the lower parts of the troposphere, the stability requirements can be significantly relaxed due to the pressure broadening of the absorption lines. To assure an absolute frequency stability of better than $60 \mathrm{MHz}$, the DFB-laser for the strongest $\mathrm{H}_{2} \mathrm{O}$-absorption line is locked to a $36 \mathrm{~m}$ multi-pass absorption cell (Aerodyne AMAC-36) filled with $80 \mathrm{~Pa}$ of pure water vapor. For this, the laser is current-modulated by a $4 \mathrm{kHz}$ sine wave which is phase-locked to the pump laser so that the seed process occurs at the zero crossing of the modulation. The current modulation results in a frequency modulation with an amplitude of about $\pm 200 \mathrm{MHz}$. Then, a standard lock-in technique is used to stabilize the DFB-laser to the center of the $\mathrm{H}_{2} \mathrm{O}$-absorption line. Locking to the center essentially makes the wavelength insensitive to changes of the water vapor pressure in the cell and to laser power fluctuations.

Since the current modulation does not only modulate the frequency but also the output power of the laser diodes, an offset has to be subtracted from the output signal of the lockin amplifier. This offset is determined from a scan over the absorption line and is usually small; and not to correct this effect would lead to a frequency error of about $100 \mathrm{MHz}$.

The other three DFB diodes are stabilized to a wavemeter (High Finesse WS7), which is continuously re-calibrated against the first DFB laser (see Fig. 16). Although the wavemeter is specified to have an absolute accuracy of better than $60 \mathrm{MHz}$, which would be sufficient to fulfill our requirements, we saw misreadings of up to $200 \mathrm{MHz}$ with changing cabin pressure of the aircraft. Therefore we kept the stabilization of the most sensitive seed laser to an absorption cell in spite of the increased complexity and weight.

Besides the requirement for an absolute frequency stability of the seed laser system, also the short-term shot-toshot stability has to be good enough not to disturb the injection seeding of the OPO. Since our OPO cavity control is only able to respond to seed laser frequency changes within a few laser shots, the short-term seed frequency jitter has to be smaller than the acceptance range of the OPO. For a good spectral purity, this range is about $1 / 100$ of the free spectral range or $\pm 20 \mathrm{MHz}$ (see Sect. 2.2 and [28]). To assess the short-term frequency variations, the following measurement was set up: The first DFB laser was locked to a strong $\mathrm{H}_{2} \mathrm{O}$-absorption line using the multi-pass cell, and a second laser was stabilized to a nominal offset of $513.6 \mathrm{MHz}$ 
Fig. 16 Seed lasers with wavelength control

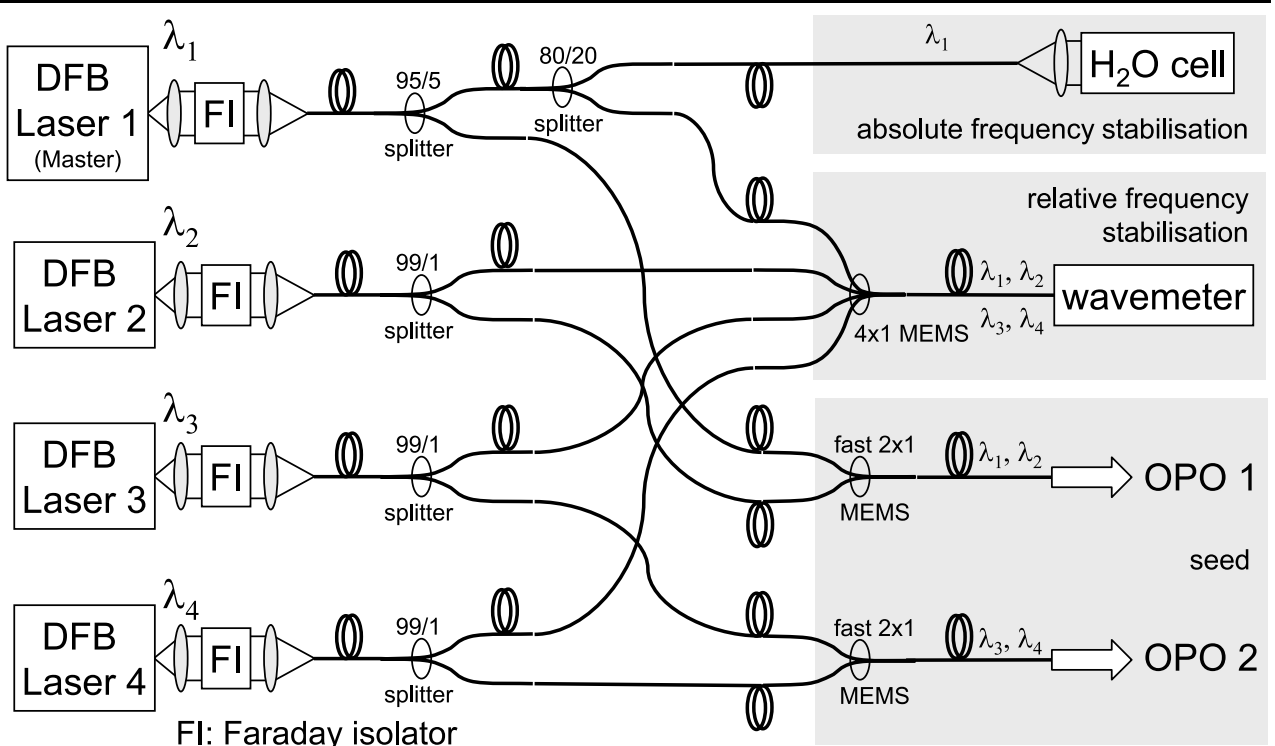

FI: Faraday isolator
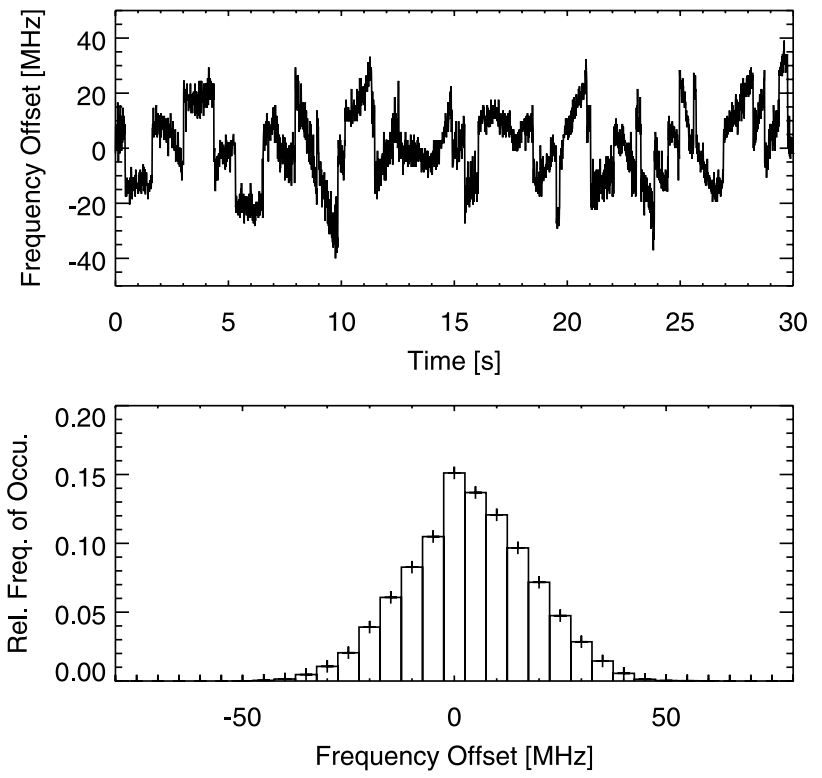

Fig. 17 Short-term frequency deviation between the $\mathrm{H}_{2} \mathrm{O}$-cell locked seed laser and a second seed laser lock to an offset of $513.6 \mathrm{MHz}$ $(1.5 \mathrm{pm})$ using the wavemeter (upper panel). The lower panel shows the histogram of the deviations for a run of $1000 \mathrm{~s}\left(10^{5}\right.$ laser shots). The standard deviation is $14.5 \mathrm{MHz}$, and the mean deviation from the $513.6 \mathrm{MHz}$ offset is $6.0 \mathrm{MHz}$

(1.5 pm) using the wavemeter. The light of the two lasers was then coupled by a polarization maintaining single-mode fiber combiner and monitored by a fast photodiode. By mixing on a square-law detector a high-frequency signal is generated which has a frequency that is exactly the difference of the frequencies of the two DFB-lasers. Figure 17 shows a time series of the difference frequency of the two DFB lasers made at the repetition rate of the laser $(100 \mathrm{~Hz})$, where the deviation from the nominal offset of $513.6 \mathrm{MHz}$ is plotted. Most of the time the shot-to-shot variations are below
$5 \mathrm{MHz}$ accompanied by a slow drift which represents no problem to the cavity control loop. Once in a while, large $20 \mathrm{MHz}$ steps occur which correspond to the smallest computer controllable current steps possible by the diode drivers (Thorlabs ITC5022), but even these are within the required bounds. The lower panel of Fig. 17 shows the histogram of a $1000 \mathrm{~s}$ run. The standard deviation is $14.5 \mathrm{MHz}$ and the mean offset from the nominal value is $6.0 \mathrm{MHz}$, which shows that the relative accuracy of the wavemeter is within the $10 \mathrm{MHz}$ bound specified by the manufacturer. It should be noted that since both lasers drift individually around their mean frequency values, the standard deviation for one laser is expected to be $\sqrt{2}$ smaller than the value of the relative difference given above.

After collimation, the radiation from the DFB lasers is fed through optical isolators with $30 \mathrm{~dB}$ isolation and then coupled into polarization-maintaining single-mode fibers. We regularly achieve coupling efficiencies of $40 \%$ to $50 \%$. All connections, power splitters, and switching optics of the seed laser system are fiber-coupled using polarizationmaintaining single-mode fibers. Two DFB-lasers are alternately switched to one OPO cavity by fiber-coupled microelectromechanical switches (MEMS). After all fiber-optic components, a total seed laser power $\approx 7 \mathrm{~mW}$ is available at the OPO cavity.

\section{Receiver}

The receiver uses a standard monostatic setup with a $48 \mathrm{~cm}$ Cassegrain telescope, which can either be mounted in nadir or zenith-viewing direction. The different wavelengths are separated by dielectric beam splitters. Standard $1 \mathrm{~nm}$ bandwidth interference filters are used to suppress the solar background. Depolarization channels are available at 532 and 


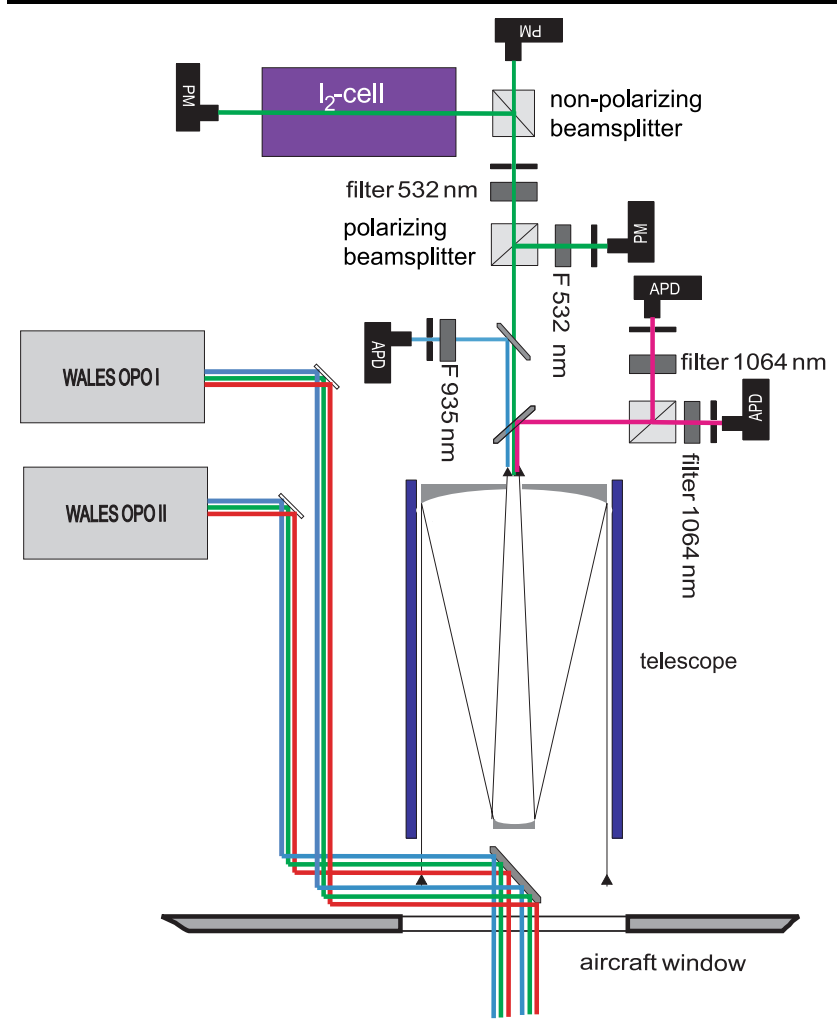

Fig. 18 Receiver layout. The detector box uses no focusing elements before beam separation by dielectric mirrors to avoid the use of achromats. All wavelengths for $\mathrm{H}_{2} \mathrm{O}$ measurements are fed through one interference filter with $1 \mathrm{~nm}$ transmission-bandwidth onto the same detector. The aerosol channels at 1064 and $532 \mathrm{~nm}$ are equipped with double polarizing beam splitters for enhanced separation. For calibration of the depolarization channels, the whole detection unit can be rotated about the optical axis of the telescope. The outgoing beams are transmitted behind the secondary mirror of the receiving telescope with a separation of $40 \mathrm{~mm}$

$1064 \mathrm{~nm}$. To enable extinction measurements at $532 \mathrm{~nm}$, part of the backscattered light is fed through a $40 \mathrm{~cm} \mathrm{I}_{2}$-cell with a suppression of aerosol scattering of better than $10^{4}$ (see Fig. 18). Since the optical layout of the iodine cell and most of the receiver optics were taken from a precursor system described in [18], only the main parameters will be given here (see Table 2).

For the $532 \mathrm{~nm}$ channels, photo-multipliers (PM) (Hamamatsu R7400-U20) are used, and avalanche photo diodes (APD) (Perkin Elmer C30955E-TC) for the infrared channels. The noise equivalent power (NEP) values given in Table 2 are calculated from measurements of the output current noise of the detectors (including amplifier and digitizer contributions) and the responsivity values taken from the individual data sheets for each detector. The APDs are temperature stabilized to $18^{\circ} \mathrm{C}$ to assure a constant responsivity. The detectors, their high-voltage power supplies, the temperature controllers (for the APD), the current amplifiers, and the analog to digital converters are integrated into small $(108 \mathrm{~mm} \times 80 \mathrm{~mm} \times 51 \mathrm{~mm})$, well-shielded modules to
Table 2 Receiver key parameters

\begin{tabular}{ll}
\hline Parameter & Value \\
\hline Telescope diameter & $480 \mathrm{~mm}$ \\
Focal length & $5 \mathrm{~m}$ \\
Transmitter coupling & monostatic \\
Field of view (all channels) & $1.6 \mathrm{mrad}$ \\
Full overlap distance & $800 \mathrm{~m}$ \\
Filter bandwidth (all channels) & $1 \mathrm{~nm}$ \\
IF-Filter transmission (all channels) & $>50 \%$ \\
I2-cell aerosol scatter suppression & $\geq 10^{4}$ \\
Detector type $1046 \mathrm{~nm} / 935 \mathrm{~nm}$ & $\mathrm{APD}$ \\
Detector type 532 nm & $\mathrm{PM}$ \\
NEP 1064 nm & $15 \mathrm{fW} / \sqrt{\mathrm{Hz}}$ \\
NEP 935 nm & $8 \mathrm{fW} / \sqrt{\mathrm{Hz}}$ \\
NEP 532 nm & $0.25 \mathrm{fW} / \sqrt{\mathrm{Hz}}$ \\
Pulse response (FWHM) (all chan.) & $100 \mathrm{~ns}$ \\
Analog/Digital converter & $14 \mathrm{bit}$ \\
Sampling rate & $10 \mathrm{MHz}(15 \mathrm{~m})$
\end{tabular}

Table 3 Flight module data

\begin{tabular}{ll}
\hline Parameter & Value \\
\hline Total weight & $450 \mathrm{~kg}$ \\
Dimensions $\mathrm{L} \times \mathrm{W} \times \mathrm{H}$ & $1.7 \mathrm{~m} \times 1.1 \mathrm{~m} \times 1.2 \mathrm{~m}$ \\
Power consumption (laser system) & $1500 \mathrm{~W}$ \\
Power consumption (total) & $2000 \mathrm{~W}$ \\
\hline
\end{tabular}

reduce the risk of electromagnetic interference from laser power supplies and other electronics like computers and aircraft intercom. From $1000 \mathrm{~s}\left(10^{5}\right.$ profiles) averages with covered detector residual baseline effects were estimated to be below $3 \times 10^{-7}$ of full scale.

\section{Flight module}

To facilitate an integration into DLR's Falcon F20 aircraft (D-CMET), a very compact setup had to be realized (see Fig. 19). Table 3 gives the physical dimensions and power consumption of the complete system. A single laser system, including pump laser, OPO, beam-conditioning optics, power supplies, and control electronics, is integrated into a single housing with dimensions of $999 \mathrm{~mm} \times 412 \mathrm{~mm} \times$ $257 \mathrm{~mm}$. Two of these units are stacked over one another.

Finite-element mechanical (FEM) simulations were performed to minimize overall weight at the given high stiffness requirements for stable transmitter/receiver overlap. The lasers and power electronics are cooled against the outside of the aircraft by a two-stage liquid cooling loop. 


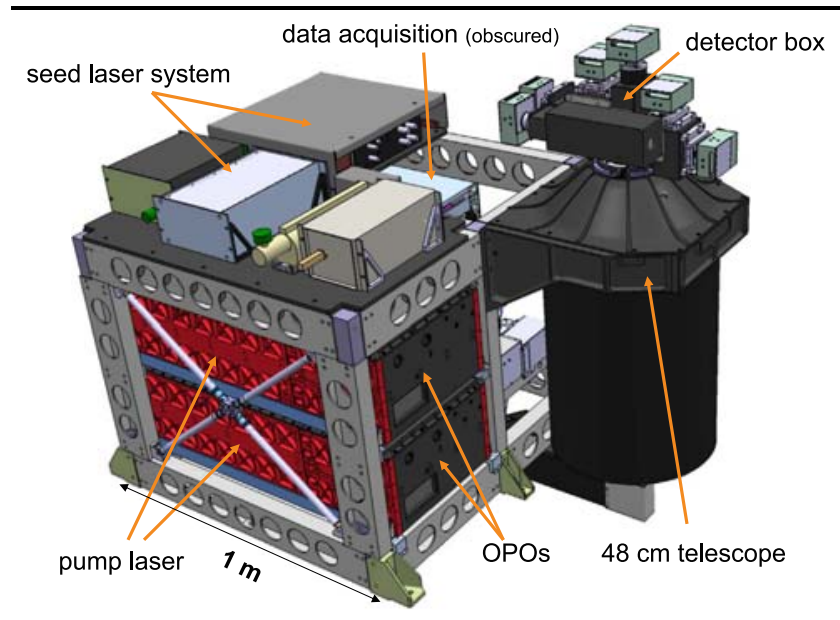

Fig. 19 Instrument rack for integration into DLR's Falcon F20 aircraft

\section{Summary}

To summarize, a new airborne water vapor differential absorption lidar has been realized. Its most important new attribute is the use of four different wavelengths in the $935 \mathrm{~nm}$ absorption band of $\mathrm{H}_{2} \mathrm{O}$ which enables the measurement of water vapor profiles from the lower stratosphere to the planetary boundary layer with high vertical resolution in all climate regions. The required wavelengths are generated by using two identical all-solid-state laser systems consisting of an injection seeded KTP OPO pumped by a diode-pumped $\mathrm{Nd}$ :YAG laser at a repetition rate of $100 \mathrm{~Hz}$. These laser transmitters feature several unique properties and significant improvements over existing systems.

The Nd:YAG pump lasers are set up in a master-oscillator power-amplifier configuration using a monolithic ring laser as the master that inherently operates in a single longitudinal mode. This passively Q-switched master laser is actively stabilized to an iodine absorption line resulting in a high absolute long-term frequency stability of better than $1 \mathrm{MHz}$, which is a prerequisite for high spectral resolution lidar measurements of aerosol extinction. The master laser is amplified by a factor of $10^{4}$ yielding a fundamental energy of each laser exceeding $400 \mathrm{~mJ}$ per pulse. The pulse width is about $8 \mathrm{~ns}$, and the beam quality is excellent $\left(M^{2} \approx 1.5\right)$. A second-harmonic conversion efficiency of $55 \%$ has been achieved using KTP as the nonlinear optical crystal resulting in pulse energies of up to $220 \mathrm{~mJ}$ at $532 \mathrm{~nm}$. The whole laser including all electronics is set-up in a rugged housing having a volume of less than 751 . The wall plug efficiency of the pump laser system to generate the pulses at $1064 \mathrm{~nm}$ is $5.3 \%$.

The OPO is set up as a four-mirror ring oscillator with two KTP crystals in a walk-off compensated configuration. Narrow-band operation of the OPOs is performed using injection seeding. For this purpose, a seed laser system has been designed using four different DFB lasers that are tuned to the respective on- and offline wavelengths. While one of the DFB lasers is absolutely stabilized using a water vapor absorption cell, the others are stabilized relative to this master laser using a wavemeter. Herewith a frequency stability of better than $20 \mathrm{MHz}$ is achieved for all seed lasers. Each two lasers seed one of the OPOs. The switching between wavelengths is performed on a shot-to-shot basis using fast polarization-maintaining fiber-coupled MEMS switches. The whole seed laser system is fully fiber-coupled resulting in high stability in a modular set-up. In order to actively match the OPO cavity length to the seed wavelengths, both OPOs use a heterodyne technique. Hereby the frequency offset between seed wavelength and every outgoing OPO pulse is measured to generate the error signal for cavity tuning. The injection seeded OPOs deliver about $60 \mathrm{~mJ}$ of output energy with a decent beam quality $\left(M^{2}<8\right)$ in $5.5 \mathrm{~ns}$ long pulses. The linewidth is $\leq 150 \mathrm{MHz}$. Usually, for lidar operation, the output energy of the OPOs is reduced to $\approx 45 \mathrm{~mJ}$ per pulse. Under these conditions, the spectral purity of the OPOs is reliably better than $99.9 \%$. The OPO signal waves and the nondepleted fundamental and second harmonic of the pump lasers are transmitted into the atmosphere, the latter after polarization filtering. The receiver features not only detectors for all transmitted wavelengths but also cross-polarized channels at 1064 and $532 \mathrm{~nm}$ to measure the depolarization of the backscattered light and an iodine vapor cell through which part of the received $532 \mathrm{~nm}$ light is transmitted to suppress aerosol backscatter to better than $10^{-4}$ in order to retrieve aerosol extinction using the HSRL technique. Since its completion the lidar system has confirmed its unique capabilities in a variety of airborne campaigns performed under different climatic conditions ranging from the Subtropics to the Arctic. The system has demonstrated its capabilities as a state-of-the-art instrument for airborne atmospheric research and also as a demonstrator for future space-borne water vapor DIAL instruments.

Acknowledgements The authors would like to thank B. Günther, G. Simmet, H. Krafczyk, and DLR's central mechanical workshop at Oberpfaffenhofen for their outstanding support during the development of the system. Special thanks to S. Berger from Rofin-Sinar GmbH and I. Freitag from Innolight $\mathrm{GmbH}$ for their help and willingness to support the modifications necessary to use their products within our project.

\section{References}

1. L. Bengtsson, K.I. Hodges, S. Hagemann, Tellus A 56, 202-217 (2004)

2. É. Gérard, D.G.H. Tan, L. Garand, V. Wulfmeyer, G. Ehret, P. Di Girolamo, BAMS 85, 237-251 (2004)

3. R.M. Schotland, J. Appl. Meteor. 13, 71-77 (1974)

4. J. Bösenberg, Appl. Opt. 37, 3845-3860 (1998)

5. W.B. Grant, Opt. Eng. 30, 40-48 (1991)

6. E.V. Browell, S. Ismail, W.B. Grant, Appl. Phys. B 67, 399-410 (1998) 
7. S. Ismail, E. Browell, Appl. Opt. 28, 3603-3615 (1998)

8. L.S. Rothman et al., J. Quantum Spectrosc. Radiat. Transf. 96, 139-204 (2005)

9. ESA, Report for Mission Selection: WALES—Water Vapour Lidar Experiment in Space. ESA SP 1279 (3), ISBN 92-9092-962-6 (2004)

10. V. Wulfmeyer, H. Bauer, P. Di Girolamo, C. Serio, Remote Sens. Environ. 95, 211-230 (2005)

11. P. Di Girolamo, A. Behrendt, C. Kiemle, V. Wulfmeyer, H. Bauer, D. Summa, A. Dörnbrack, G. Ehret, Remote Sens. Environ. 112, $1552-1568$ (2008)

12. V. Wulfmeyer, A. Behrendt, H.-S. Bauer, C. Kottmeier, U. Corsmeier, A. Blyth, G. Craig, U. Schumann, M. Hagen, S. Crewell, P. Di Girolamo, C. Flamant, M. Miller, A. Montani, S. Mobbs, E. Richard, M.W. Rotach, M. Arpagaus, H. Russchenberg, P. Schlüssel, M. König, V. Gärtner, R. Steinacker, M. Dorninger, D.D. Turner, T. Weckwerth, A. Hense, C. Simmer, BAMS 89, 1477-1468 (2008)

13. M. Esselborn, M. Wirth, A. Fix, P. Mahnke, G. Ehret, in Proceedings of the 24th International Laser Radar Conference, Boulder, CO (USA), 2008, pp. 357-360. ISBN 987-0-615-21489-4

14. A. Fix, M. Wirth, M. Esselborn, A. Amediek, P. Mahnke, S. Rahm, R. Simmet, A. Schäfler, C. Kiemle, A. Dörnbrack, G. Ehret, in Proceedings of the 24th International Laser Radar Conference, Boulder, CO (USA), 2008, pp. 1005-1009. ISBN 987-0-61521489-4

15. G. Ehret, K.P. Hoinka, J. Stein, A. Fix, C. Kiemle, G. Poberaj, J. Geophys. Res. 104, 31351-31359 (1999)

16. G. Poberaj, A. Fix, A. Assion, M. Wirth, C. Kiemle, G. Ehret, Appl. Phys. B 75, 165-172 (2002)

17. I. Freitag, A. Tünnermann, H. Welling, Opt. Lett. 22, 706-708 (1997)

18. M. Esselborn, M. Wirth, A. Fix, M. Tesche, G. Ehret, Appl. Opt. 47, 346-358 (2008)

19. S. Gerstenkorn, P. Luc, Atlas du Spectre D'Asorption de la Molecule D'Iode, Atlas III (CNRS, Paris, 1978)

20. M.S. Fee, K. Danzmann, S. Chu, Phys. Rev. A 45, 4911-4924 (1992)

21. S. Gangopadhyay, N. Melikechi, E.E. Eyler, J. Opt. Soc. Am. B 11, 231-241 (1994)

22. T. Schröder, C. Lemmerz, O. Reitebuch, M. Wirth, C. Wührer, R. Treichel, Appl. Phys. B 87, 437-444 (2007)

23. R. Fluck, M.R. Hermann, L.A. Hackel, Appl. Phys. B 70, 491-498 (2000)
24. Lasers and laser-related equipment-test methods for laser beam parameters-beam widths, divergence angle and beam propagation factor. ISO11146, International Organization for Standardization (1999)

25. M. Ostermeyer, G. Klemz, P. Kubina, R. Menzel, Appl. Opt. 41, 7573-7582 (2002)

26. M. Ostermeyer, P. Knappe, R. Menzel, V. Wulfmeyer, Appl. Opt. 44, 582-590 (2005)

27. B. Boulanger, M.M. Fejer, R. Blachman, P.F. Bordui, Appl. Phys. Lett. 65, 2401-2403 (1994)

28. P. Mahnke, H. Klingenberg, A. Fix, M. Wirth, Appl. Phys. B 89, 1-7 (2007)

29. G. Anstett, A. Borsutzky, R. Wallenstein, Appl. Phys. B 76, 541545 (2003)

30. G. Anstett, M. Nittmann, R. Wallenstein, Appl. Phys. B 79, 305313 (2004)

31. A.V. Smith, M.S. Bowers, J. Opt. Soc. Am. B 18, 706-713 (2001)

32. A.V. Smith, D.J. Armstrong, J. Opt. Soc. Am. B 19, 1801-1814 (2002)

33. D.J. Armstrong, A.V. Smith, Opt. Lett. 31, 380-382 (2006)

34. G. Arisholm, O. Nordseth, G. Rustad, Opt. Express 12, 4189-4197 (2004)

35. C.J. Grund, R.M. Banta, J.L. George, J.N. Howell, M.J. Post, R.A. Richter, A.M. Weickmann, J. Ocean. Atmos. Technol. 18, 376$393(2001)$

36. R.T. White, Y. He, B.J. Orr, M. Kono, K.G.H. Baldwin, J. Opt. Soc. Am. B 21, 1577-1585 (2004)

37. R.T. White, Y. He, B.J. Orr, M. Kono, K.G.H. Baldwin, J. Opt. Soc. Am. B 21, 1586-1594 (2004)

38. R.T. White, Y. He, B.J. Orr, M. Kono, K.G.H. Baldwin, Opt. Express 12, 5655-5660 (2004)

39. R.T. White, Y. He, B.J. Orr, M. Kono, K.G.H. Baldwin, J. Opt. Soc. Am. B 24, 2601-2609 (2007)

40. A. Fix, R. Wallenstein, J. Opt. Soc. Am. B 13, 2484-2497 (1996)

41. G. Anstett, R. Wallenstein, Appl. Phys. B 79, 827-836 (2004)

42. L.A. Rahn, Appl. Opt. 24, 940-942 (1985)

43. S.W. Henderson, E.H. Yuen, E.S. Fry, Opt. Lett. 11, 715-718 (1986)

44. V. Wulfmeyer, M. Randall, A. Brewer, R.M. Hardesty, Opt. Lett. 25, 1228-1230 (2000)

45. M. Kamp, J. Hofmann, A. Forchel, F. Schäfer, J.P. Reithmaier, Appl. Phys. Lett. 74, 483-485 (1999) 